\title{
Cytochrome Oxidase Repair during Treatment of Copper Deficiency: Relation to Mitochondrial Turnover*
}

\author{
Peter R. Dallman $\ddagger$ with the technical assistance of David Loskutoff \\ (From the Department of Pediatrics, Lt. Joseph P. Kennedy, Jr. Laboratories of Molecular \\ Medicine, Stanford University School of Medicine, Palo Alto, California)
}

\begin{abstract}
The repair of cytochrome oxidase depletion during the treatment of copper deficiency was studied in the rat. The purpose of this study was to distinguish the role of new cell production from the possibly more specific role of mitochondrial turnover in determining the rate of this repair.

In rats on a copper-deficient regimen until 2.5-3 months of age, activities of cytochrome oxidase expressed as per cent of control were as follows: skeletal muscle (quadratus lumborum), 18\%; heart, $27 \%$; liver, $34 \%$; and intestinal mucosa, 34\%. After 2-3 days of dietary supplementation with cupric acetate, repair of decreased cytochrome oxidase activity in intestinal mucosa is complete. Histochemical studies indicated that this repair starts in the newly differentiating cells at the base of the villus and then progresses toward the tip of the villus at a rate approximating the normal rate of migration of the mucosal cells. In liver and skeletal muscle, cytochrome oxidase activity returned to control values after 10-15 days of treatment with cupric acetate. In heart muscle, control values were approached more slowly as indicated both by activity of the enzyme and by mitochondrial difference spectra which reflect enzyme concentration.

Although cytochrome oxidase repair in the intestine appeared to be limited by the rate of production of new mucosal cells, the rate of repair in liver and skeletal muscle was several times too rapid to be accounted for by known rates of new cell production. Incorporation of tritiated thymidine into DNA in these tissues in both the deficiency state and during repair indicated no major differences in new cell production compared to that of control animals. However, the time required for cytochrome oxidase repair in liver was similar to the turnover reported for other mitochondrial constituents in this tissue. The rate of cytochrome oxidase repair may therefore be more directly determined by the rate of synthesis of new mitochondrial material than by the rate of production of new cells.
\end{abstract}

\section{Introduction}

The clinical management of nutritional deficiency states is guided largely by the anticipated response to an improved diet. Responsiveness to dietary

* Received for publication 12 June 1967 and in revised form 17 July 1967.

Part of this work was presented at the annual meeting of the Western Section of the American Federation of Clinical Research, January 1967, and appears in abstract in Clin. Res. 1967. 15: 108.

$\ddagger$ Recipient of U. S. Public Health Service research career program award HE-07184. treatment can vary widely with the specific deficiency and the circumstances of its development. Whereas hypoglycemia produced by fasting can be reversed in less than an hour, stunting of growth in an undernourished young animal can be permanent (1). Among the factors affecting the ca-

These investigations were supported by grants in aid from the U. S. Public Health Service, HE 10050, and from the John A. Hartford Foundation.

Address requests for reprints to Dr. Peter R. Dallman, Department of Pediatrics, Stanford University School of Medicine, Palo Alto, Calif. 94304. 
pacity for repair is the rate at which certain tissues can grow or replace themselves by the production of new cells. An example is the deficiency of hemoglobin that results from iron deprivation. The repair of this deficiency occurs only with the production of newly differentiating, normal erythrocytes and is not possible in the previously hemoglobin-depleted, mature cells (2-5). Similarly, the repair of intestinal cytochrome $c$ depletion during treatment of iron deficiency appears to be limited by the rate of production of new mucosal cells $(6,7)$. Since cytochrome $c$ is an integral component of normal mitochondria it is possible that its replacement is more specifically dependent upon production of new mitochondrial material than upon the differentiation of newly produced cells. These possibilities could not be distinguished in the iron-deficient rat because of the very rapid rate of renewal of intestinal mucosal cells. Furthermore, the interpretation of rates of repair in other cytochrome deficient tissues was complicated by marked growth retardation in the depleted animals and by a very rapid rate of "catch-up" growth after initiation of iron supplementation (6). This problem is largely circumvented in the copper-deficient rat since a profound deficiency in mitochondrial cytochrome oxidase is readily produced in many tissues with only minor depression of body growth. In the present study we attempt to distinguish the role of production of new differentiating cells from the possibly more specific role of mitochondrial turnover in determining the rate of replacement of cytochrome oxidase during the treatment of copper deficiency. Our results suggest that accretion of new mitochondrial material could determine the rate of restitution of this copper-containing heme protein.

\section{Methods}

Male rats of the Wistar strain were placed on a low copper regimen as follows. Mothers with only the males of their litters were provided 10 days after birth with a diet, containing $0.39 \mathrm{ppm}$ copper, that consisted of dried, partially skimmed milk (Dryco-Borden, Borden Co., New York, N. Y.) supplemented with a vitamin and mineral formula (8). Because nursing rats start to nibble at the diet intended for their mother after about 15 days of age, when their eyes begin to open, initiation of the deficient dietary regimen before weaning was required for prompt production of copper deficiency. The rats were weaned at 21 days of age and assigned to deficient and control groups. Distilled water was provided ad lib. to the deficient animals. Control rats were placed on the same diet and in addition received $10 \mathrm{mg}$ of copper as cupric acetate per liter of drinking water, approximately the amount of copper ingested by rats on a commercial stock diet (9). The groups of deficient animals were maintained on the copper-poor diet until they were 5570 days old. Repletion of these rats was accomplished by providing them with $10 \mathrm{mg}$ of copper per liter of drinking water, after an initial dose of $0.5 \mathrm{mg}$ of copper by gastric tube.

Rats were killed by decapitation and the tissues to be studied were immediately removed. Cytochrome oxidase activity in tissue homogenates was estimated by determining the rate of oxidation of reduced cytochrome c spectrophotometrically, as described by Cooperstein and Lazarow (10). The low cytochrome oxidase activity of copper deficient tissues could not be altered by the presence of $10^{-7} \mathrm{M}$ cupric sulfate in the final reaction mixture. This concentration of copper is the highest that could be derived from normal tissue (9).

Cytochrome-oxidase was histochemically localized in sections of upper jejunum by the method of Burstone (11) under the conditions previously described (6). Since the intensity of staining is a function of both cytochrome $c$ and cytochrome oxidase (11), we will refer to the activity observed histochemically as "cytochrome-oxidase."

Cytochrome $c$ was determined by the method of Rosenthal and Drabkin (12) with minor modifications previously described (13). The copper content of the liver was determined by the method of Brown and Hemingway (14). Venous hemoglobin was measured as cyanmethemoglobin (15). Protein was determined by the method of Lowry et al. (16).

Rates of incorporation of tritiated thymidine into DNA were determined as follows. An intracardiac injection of $1 \mu \mathrm{c}$ of thymidine- ${ }^{3} \mathrm{H}$ (15 $\left.\mathrm{c} / \mathrm{mmole}\right)$ per $\mathrm{g}$ of body weight was given between 8 and $10 \mathrm{a} . \mathrm{m}$. The rats were killed $2 \mathrm{hr}$ later and tissues were removed immediately. Nucleic acids were extracted from tissue homogenates by the method of Schneider (17) and $0.5 \mathrm{ml}$ aliquots of the extract were added to scintillation vials containing $15 \mathrm{ml}$ of Bray's medium (18). Radioactivity was measured with $12 \%$ efficiency in a Packard Tri-Carb scintillation counter (Packard Instrument Co., Inc., Downers Grove, III.). An internal standard was utilized to correct for quenching. DNA was determined by the method of Dische (19).

The relative amounts of various cytochromes present in mitochondria were estimated as follows. Heart muscle was finely minced and then homogenized in 9 parts $(\mathrm{w} / \mathrm{v})$ of $0.25 \mathrm{M}$ sucrose, first in a ground glass homogenizer to break up larger particles of tissue and then in a glass homogenizer with a Teflon pestle. The twice-washed mitochondrial fraction, prepared in $0.25 \mathrm{M}$ sucrose by differential centrifugation as described by Schneider (20), contained $40-50 \%$ of the cytochrome oxidase activity present in the whole homogenate. The mitochondrial pellet was solubilized in $1 \mathrm{ml}$ of $2 \%$ deoxycholate. The absorption spectrum of a sample reduced with a few milligrams of sodium dithionite was then 
read against an oxidized aliquot as a blank, in a Zeiss spectrophotometer, at intervals of $2 \mathrm{~m} \mu$ at $20^{\circ}-25^{\circ} \mathrm{C}$.

\section{Results and Discussion}

Rats fed the copper-deficient diet until 2-3 months of age resembled control animals in their appearance except for a slight pallor apparent in the tail, ears, and eyes. The mean weights of individual groups of deficient rats during this period were only $3-15 \%$ below those of control animals of the same age. After copper repletion, very little catch-up growth was evident. The growth curves of two representative groups of animals are shown in Fig. 1. The weight gain of rats during repletion averaged no more than about $3 \%$ per day compared to $2 \%$ for deficient and $2.5 \%$ for control animals.

\section{Cytochrome oxidase activity}

Cytochrome oxidase activities obtained in an initial group of animals are shown in Table I. Anemia in the deficient animals was severe, but, after 8 days of copper treatment, hemoglobin concentrations had returned toward normal. Cytochrome oxidase activity in the copper-deficient animals was markedly depressed in several tissues, as previously observed by Cohen and Elvehjem (21), Schultze (22), Gallagher et al. (23), and Gubler et al. (24). In the present study, the deficiency was most marked in liver, jejunum, heart, and the quadratus lumborum muscle. As in previous studies, brain and kidney $(23,24)$ were partially or entirely spared. It is of interest that both in copper-deficient yeast and in copper-deficient rat liver only the heme portion of the cytochrome oxidase

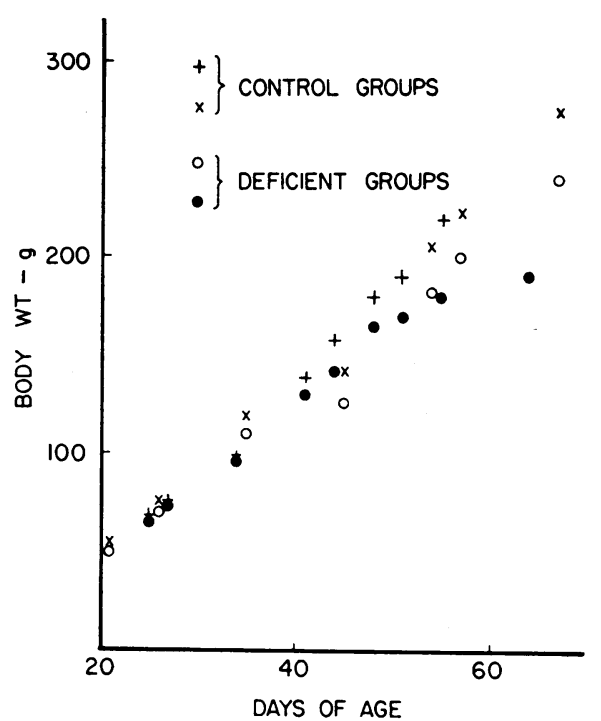

Fig. 1. Growth of RePresentative Groups of rats ON THE LOW COPPER AND CONTROL REGIMENS. Each point represents the mean of $12-30$ animals.

molecule appears to be depleted; the inactive apoprotein is present in nearly normal amounts. ${ }^{1}$

Specificity of cytochrome oxidase deficiency resulting from copper depletion. Tissues severely deficient in cytochrome oxidase showed no depression in cytochrome $c$ concentration, a finding consistent with previous observations. In the present study, the cytochrome $c$ concentration in heart muscle in four copper-deficient animals was $296 \pm$ $8 \mu \mathrm{g} / \mathrm{g}$ (mean $\pm \mathrm{SE}$ ) compared to $227 \pm 13$ in the controls. Cytochrome $c$ in the quadratus lumborum was $57 \pm \mu \mathrm{g} / \mathrm{g}$ in four deficient animals and

1 Wohlrab, H., and E. E. Jacobs. To be published. Abstract to appear in the 1967 Proceedings of the 7th International Congress of Biochemistry, Tokyo.

TABLE I

Cytochrome oxidase repair with treatment of copper deficiency

\begin{tabular}{|c|c|c|c|c|c|c|c|c|}
\hline Rats & Wt. & Hgb. & Liver & Jejunum & Heart & $\begin{array}{l}\text { Quadratus } \\
\text { lumborum } \\
\text { muscle }\end{array}$ & Brain & Kidney \\
\hline & $g$ & $\mathrm{~g} / 100 \mathrm{ml}$ & \multicolumn{6}{|c|}{ Cytochrome oxidase activity, units* } \\
\hline $\begin{array}{l}\text { Copper- } \\
\text { deficient }\end{array}$ & 259 & 7.6 & 7.8 & $\cdot 2.6$ & 5.7 & 0.8 & 8.7 & 18.1 \\
\hline $\begin{array}{l}\text { Control } \\
P\end{array}$ & 272 & $\begin{array}{l}15.7 \\
<0.001\end{array}$ & $\begin{array}{l}22.6 \\
<0.001\end{array}$ & $\begin{array}{c}7.6 \\
<0.01\end{array}$ & $\begin{array}{l}20.7 \\
<0.001\end{array}$ & $\begin{array}{c}4.5 \\
<0.001\end{array}$ & $\begin{array}{l}10.6 \\
<0.2\end{array}$ & 20.5 \\
\hline 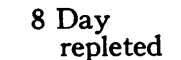 & 288 & 12.5 & 20.9 & 7.6 & 14.2 & 3.6 & 11.1 & \\
\hline $\begin{array}{l}\text { Control } \\
P\end{array}$ & 299 & 14.1 & 21.4 & 7.4 & $\begin{array}{l}19.6 \\
<0.05\end{array}$ & 4.2 & 10.2 & \\
\hline
\end{tabular}

${ }^{*} \Delta \log$ (ferrocytochrome $c$ ) per minute for a 1:100 tissue dilution. 
$65 \pm 5$ in six control rats. The slight elevation of cytochrome $c$ in the heart muscle of the deficient group is similar to that observed by Gubler, Cartwright, and Wintrobe (24) and may be related to the marked cardiac hypertrophy observed in these rats. The difference spectra of the heart mitochondria from copper-deficient animals (described below) also indicate that the effect of copper deficiency upon cytochrome oxidase is a relatively specific one and does not affect the other cytochromes. In addition, the protein content per gram of tissue weight in deficient animals was similar to that in the control.

Cytochrome oxidase repair. After 8 days of copper treatment, cytochrome oxidase repair appears to have progressed well towards completion, as shown in Table I. Only heart muscle cytochrome oxidase remained significantly below control values. The rates of cytochrome oxidase repair were determined in the four severely affected tissues in an additional group of animals. Rats were killed at intervals between $2 \mathrm{hr}$ and 20 days after initiation of copper treatment. At each of these times, litter mate control animals were also studied. The response of cytochrome oxidase activity to copper treatment in intestinal mucosa, liver, skeletal muscle, and heart is shown in Fig. 2. In intestinal mucosa, the repair of cytochrome oxidase activity is almost complete by 2 days. In liver and skeletal muscle, repair is complete between 10 and 15 days, while in heart muscle, control values seem to be approached more slowly.

Liver copper was assayed during the course of repletion in order to determine how rapidly copper stores were replenished. As shown in Fig. 3, copper accumulates rapidly after initiation of repletion. After 2 days, it has risen more than halfway toward control values and by 5 days it is equivalent to control concentrations. It is unlikely, therefore, that the much slower response of liver cytochrome oxidase is due to limited copper availability.

Intestinal mucosa. The strikingly rapid repair of intestinal cytochrome oxidase activity in homogenates was confirmed by histochemical studies

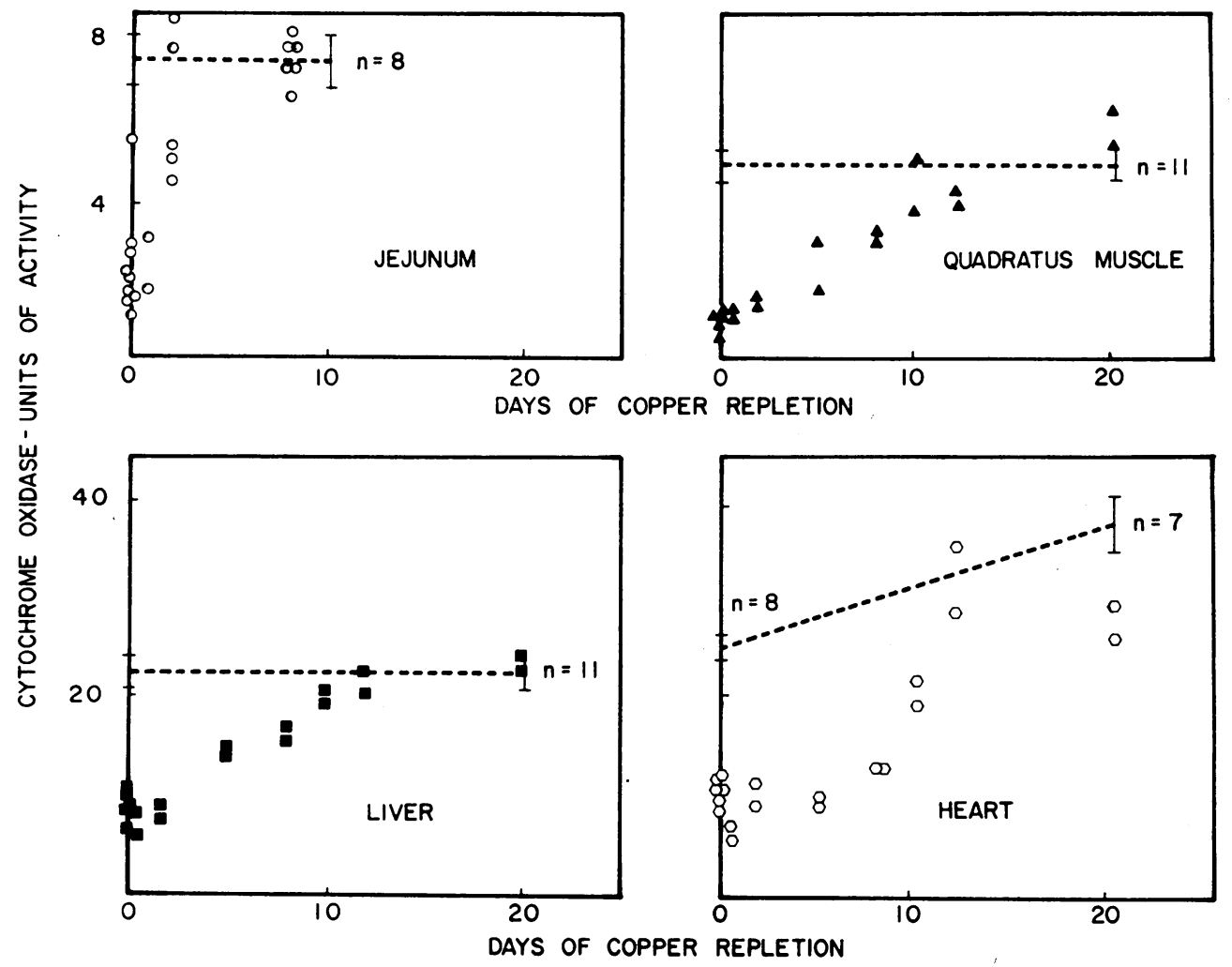

Fig. 2. Cytochrome OXIDASE REPAIR WITH TREATMENT OF COPPER DEFiCIENCY. The mean of the control values is shown by the dashed line with the standard error of the mean indicated by the brackets. 


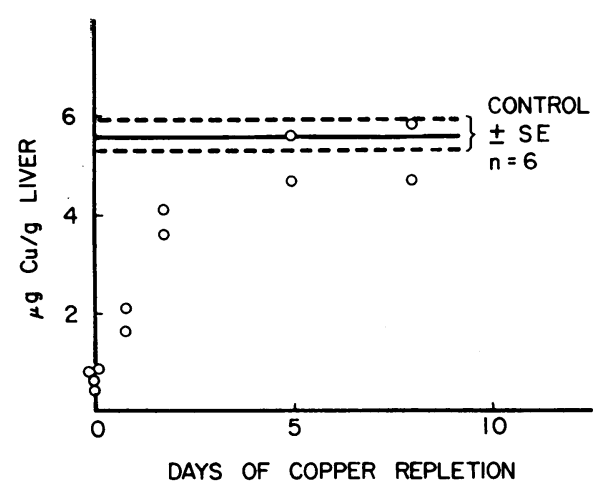

Fig. 3. Copper CONTENT OF THE Liver DURING THE COURSE OF TREATMENT OF COPPER-DEFICIENT RATS. Control values are approached rapidly and are attained within 5 days of initiation of repletion.

of the jejunal mucosa. These studies permitted us to localize early repair of "cytochrome-oxidase" in the newly differentiating cells at the base of the villus, as was previously observed during the repair of cytochrome $c$ after iron deficiency (6). In the normal animal the mucosal cells are intensely dyed by the blue-black "cytochrome-oxidase" stain $(6,11)$. Under high magnification the stain is granular and corresponds to the mitochondrial localization of cytochrome oxidase. In the copper-deficient rats, the intensity of staining was markedly decreased. Fig. 4 shows a section of jejunum from a deficient rat $24 \mathrm{hr}$ after initiation of copper treatment. The newly produced cells lining the lower portion of the villi show the intense "cytochrome-oxidase" staining characteristic of the control animals. Cells lining the tips of the villi, which presumably had differentiated during the period of deficiency, retain the pale appearance observed in the untreated rats. In the jejunal mucosa, therefore, the rate of "cytochromeoxidase" repair appears limited by the rate of production of new cells. However, since the entire population of mature mucosal cells is renewed every 2 days (25), many cell components must of necessity be produced as a function of the rate of cell differentiation and be destroyed with the death of cell. It is therefore difficult in this tissue, because of its rapid turnover, to distinguish the role of mitochondrial production from that of cell differentiation in the regulation of cytochrome oxidase repair.

Heart muscle. Interpretation of the rate of repair of cardiac cytochrome oxidase depletion, ex- pressed on a tissue weight basis, was complicated by the marked cardiac hypertrophy consistently observed in the copper-deficient rats. This hypertrophy regressed within 20 days of copper treatment, as shown in Fig. 5. A further complicating factor was the normal developmental change in cardiac cytochrome oxidase activity during the period of the experiment (Fig. 2). To partially circumvent these problems, we determined cytochrome oxidase more directly, utilizing its characteristic $\propto$ absorption peak at $605 \mathrm{~m} \mu$ (26). This method permits the use of the other cytochromes as a reference, and also has the advantage of reflecting cytochrome oxidase concentration rather than activity. The solubilized heart mitochondria from copper-deficient animals yielded a clear red solution that, after reduction, lacked a distinct cytochrome oxidase peak (Fig. 6). Control samples were distinctly more green and had a high $\propto$ ab-

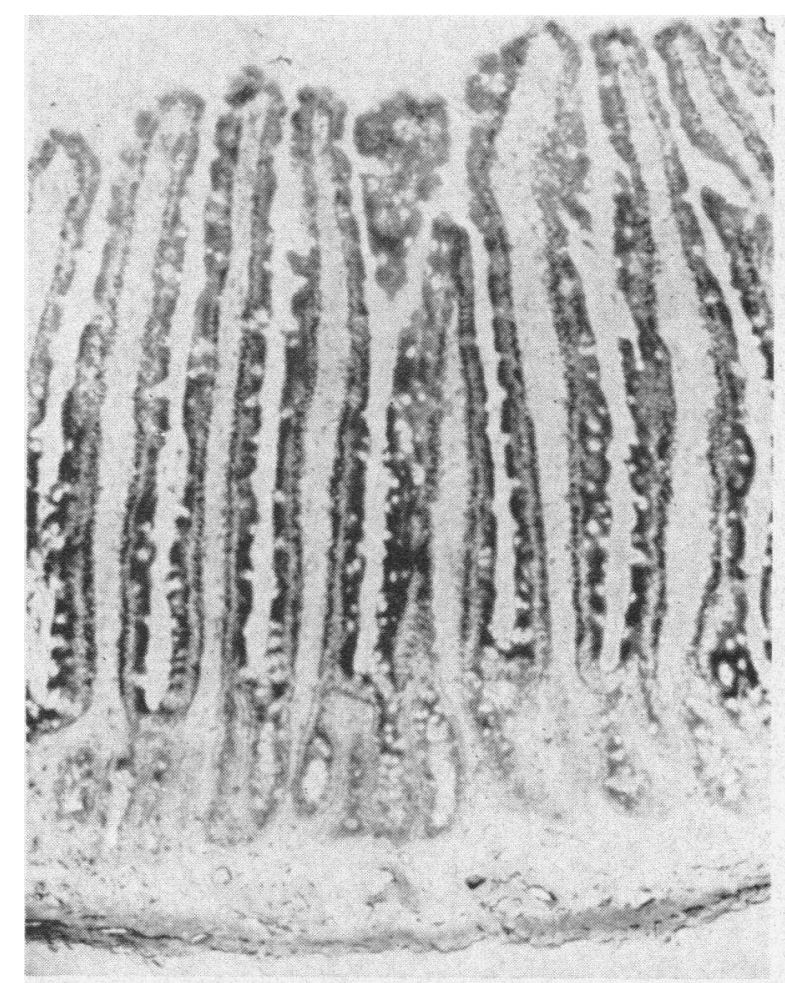

Fig. 4. Distribution OF CYTOCHROME OXIDASE ACTIVITY IN THE JEJUNUM OF A RAT ON THE COPPER-DEFICIENT REGIMEN, 24 HR AFTER INITIATION OF COPPER REPLETION $(\times 100)$. The intense staining characteristic of control samples is seen in mucosal cells lining the lower $2 / 3$ of the villi. The paler staining cells lining the tips of the villi resemble the mucosal cells in untreated copperdeficient animals. 


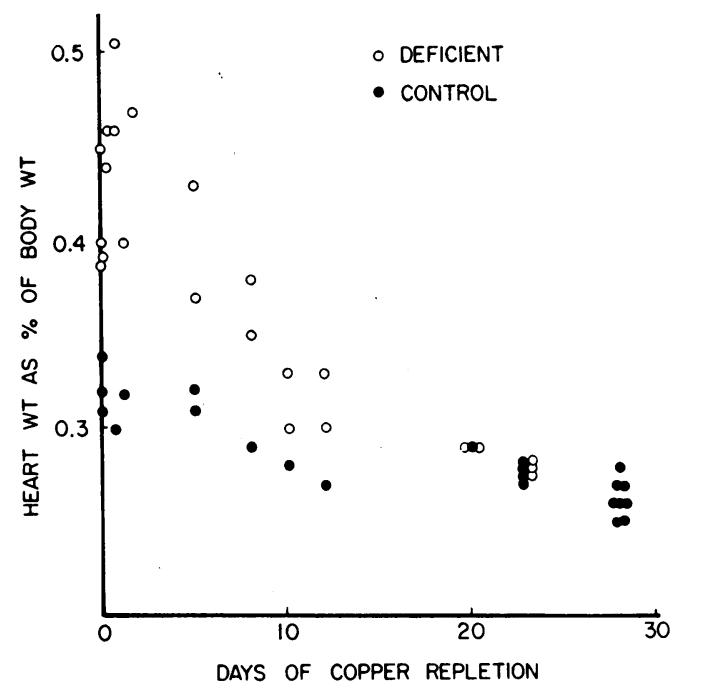

Fig. 5. REgRession OF CARDIAC HYPERTROPHY AFTER TREATMENT OF COPPER DEFICIENCY. Repair of cardiac hypertrophy is complete within 20 days of initiation of repletion.

sorption peak at $605 \mathrm{~m} \mu$. In the copper-deficient animal, the height of absorption peak between 550 and $560 \mathrm{~m} \mu$, which reflects the concentrations of cytochrome $c, c_{1}$, and $b$, was equal to or slightly greater than that observed from heart samples of comparable weight obtained from control animals. The changes in the cytochrome oxidase peak at 605 $\mathrm{m} \mu$ were estimated by using the $560 \mathrm{~m} \mu$ peak as a reference. The curves shown in Fig. 6 were normalized by equalizing the height of this reference peak above the $500 \mathrm{~m} \mu$ base line reading. The difference spectra confirm the findings of previous investigators who, employing other methods, determined that cytochrome oxidase concentration, as well as activity, is diminished in copper deficiency (23), whereas the other cytochromes are not depleted. The rate of cardiac cytochrome oxidase repair can be estimated from the change in height of the absorption peaks at $605 \mathrm{~m} \mu$. Additional curves obtained after 8,24 , and 50 days of repletion were in the anticipated intermediate positions but were eliminated from Fig. 6 for the sake of clarity. As previously suggested by the data in Table I and Fig. 2, the rate of repair appears to be rapid in the first 15 days of treatment, but slows subsequently. Even 50 days after copper repletion, repair of cytochrome oxidase does not appear to be entirely complete.

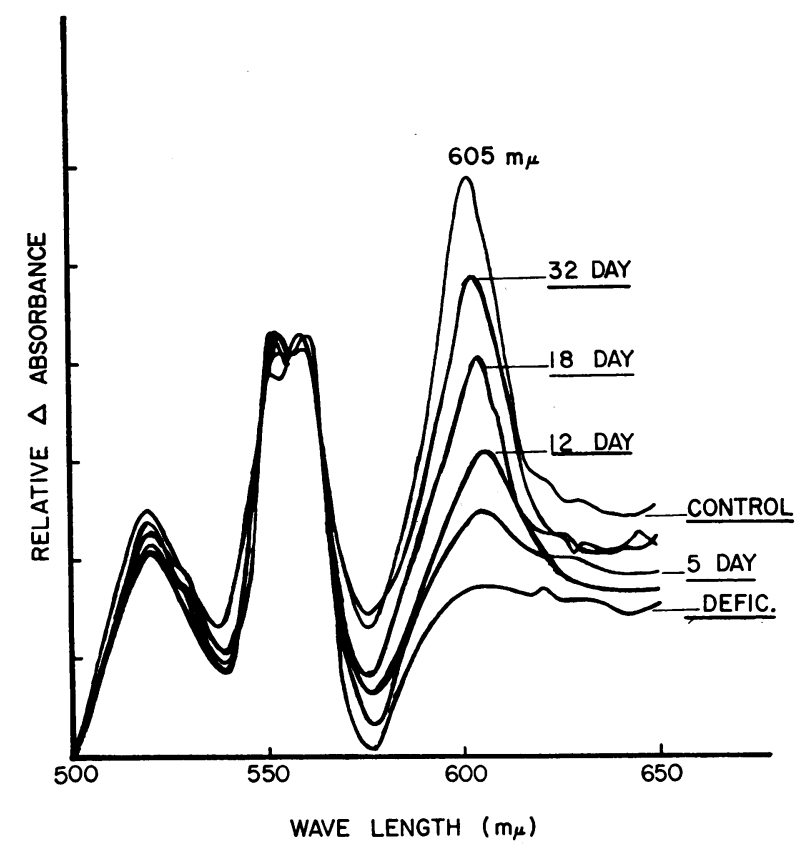

Fig. 6. DifFERENCE SPECTRA OF DEOXYCHOLATE-TREATED HEART MITOCHONDRIA DURING TREATMENT OF COPPER DEFICIENCY. The extent of cytochrome oxidase repair is indicated by the height of the $\propto$ absorption peak of cytochrome oxidase at $605 \mathrm{~m} \mu$. 
Rates of cell renewal in the copper-deficient and -repleted animal: liver and skeletal muscle

Cytochrome oxidase repair in liver and skeletal muscle is complete after 10-15 days of copper treatment. If this repair were restricted to newly produced cells, an entirely new cell population would have to be generated within this period. In the normal rat, however, the rate of cell replication in these tissues $(25,27)$ could account for only a small fraction of the repair observed. DNA production in liver and muscle is normally slow in rats between 2 and 3 months of age, and growth during this period is due more to increase in cell size than to cell multiplication (28). If this is also the case in the copper-deficient animal, then cytochrome oxidase repair must occur in other than newly produced cells. However, a marked acceleration of the normal rate of cell production during copper repletion could not be excluded. This possibility was suggested by the accelerated production of red cell precursors, reflected in a reticulocytosis, that occurs during recovery from a variety of nutritional deficiency states. We therefore investigated the possibility of a similar phenomenon occurring in solid tissues, utilizing the rate of incorporation of tritiated thymidine into DNA as an estimate of the rate of production of new cells. Although it is difficult to derive absolute rates of cell synthesis by this method, relative rates of DNA synthesis in two groups of animals can be compared. Untreated copper-deficient rats and deficient animals treated with copper for 8 days were compared with litter mate controls. The 8 day repletion point was selected from Fig. 2 as representative of a period of rapid cytochrome oxidase repair. Jejunal mucosa was studied in addition to liver and skeletal muscle as shown in Fig. 7. The upper half of the figure shows no marked differences in rates of new cell production between copper-deficient and control animals as indicated by incorporation of tritiated thymidine. The lower half of the figure also shows no significant difference in DNA synthesis between deficient animals treated with copper and the controls. Smaller groups of animals studied 2, 4, 6, and 12 days after copper repletion also failed to indicate any major change in rate of DNA synthesis. The additional observation that DNA content per gram of weight in each tissue studied was

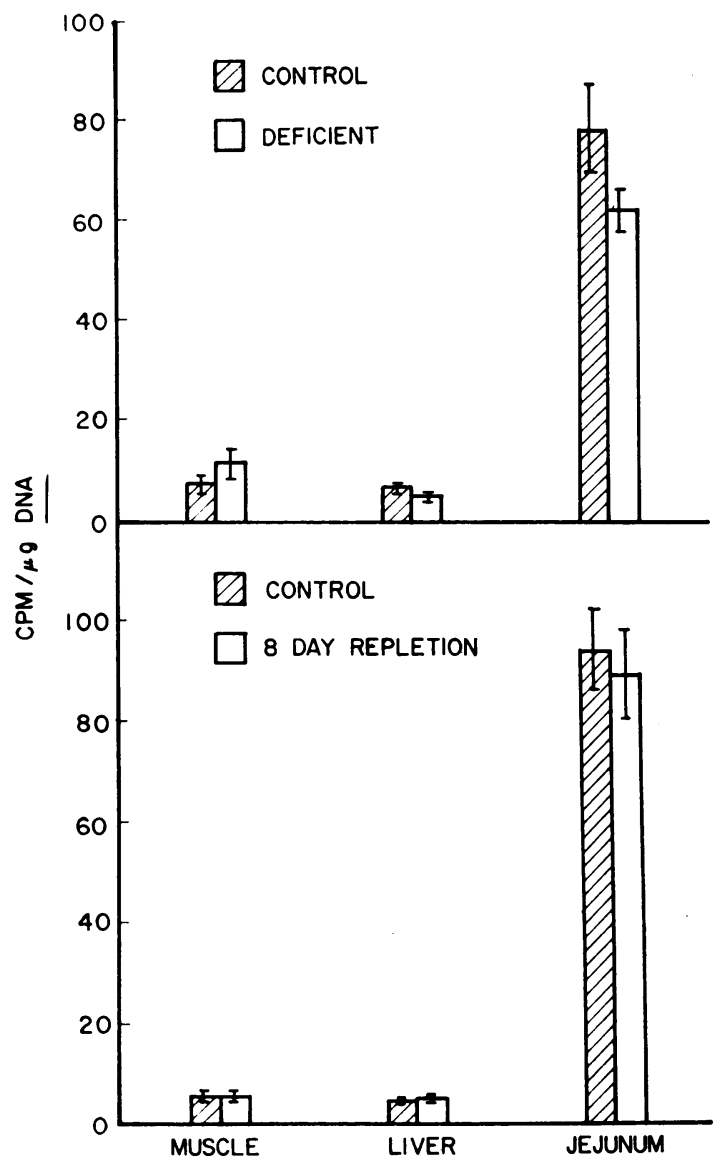

Fig. 7. Tritiated thymidine incorporation into DNA DURING REPAIR OF COPPER DEFICIENCY. No significant difference is observed between control and deficient or control and repleted animals. Standard errors of the means are indicated by brackets. Each column represents 4 control or 7-9 experimental animals.

similar in the experimental and control groups supports the conclusions that a decreased rate of cell replication is not a major feature of copper deficiency in the tissues studied, and that cytochrome oxidase repair in muscle and liver cannot be attributed entirely to the production of new cells.

\section{Cytochrome oxidase repair as a function of mito- chondrial turnover}

Since cytochrome oxidase is a firmly bound component of mitochondria, it is possible that the rate of repair of this enzyme depends upon the rate of production of new mitochondria or upon the rate of production of other mitochondrial constituents. If this were the case, repair would not 
be complete until these mitochondrial constituents within a tissue had been completely renewed. The period required for complete repair would then be similar to the turnover time of other mitochondrial components. If, however, reconstitution of cytochrome oxidase were possible within preexisting mitochondrial units, normal enzyme values might be attained far more rapidly. It is therefore pertinent to compare the rate of cytochrome oxidase repair to the available estimates of "mitochondrial life-span" obtained after pulse labeling with radioactive precursors. In rat liver mitochondria, immediately after an initial peak there is a strikingly similar rate decline in the specific activities of cytochrome $c$, (29), two protein fractions $(29,30)$, lecithin (30), and total lipid (29, $30)$. The estimated half-life of these mitochondrial components is about 6-8 days during the 2 wk after isotope administration (30) and 9-10 days during the subsequent 2 wk period $(29,30)$. Recycling of isotope is cited as a likely source of error in both studies and lends greater weight to the first figure. Neubert, Bass, and Helge (31) estimate a similar half-life of 8-9 days for the DNA in rat liver mitochondria. The parallel rates of decay in all mitochondrial components studied suggest that the rates of synthesis and degradation of these components are interdependent. Furthermore, a comparison of mitochondrial and nuclear DNA turnovers indicates a much shorter lifespan for liver mitochondria than for the liver cell itself $(31)$.

At present, no clear description of mitochondrial growth, division, and death has emerged. But, there is increasing evidence that mitochondrial DNA plays a role in the replication of these organelles (32). However, it also appears that only a relatively small proportion of mitochondrial protein, largely the nonpolar fraction, is actually synthesized within mitochondria (33-35). Other proteins, particularly the soluble enzymes and perhaps also cytochrome oxidase, appear to be synthesized in the microsomal fraction, presumably under nuclear control.

Although a detailed description of the cellular events leading to cytochrome oxidase production and repair is not yet possible, the present study suggests a relationship between the rate of this repair and the rate of production of other mitochondrial constituents. Neuberger and Richards
(5) have suggested that protein turnover may be estimated during treatment of deficiency states from the period required for a depleted protein to be restored to its normal concentration. According to the calculation of Segal and Kim (36), the half-life of such a protein is equivalent to the period between the termination of the initial deficient steady-state concentration by treatment and the time when that concentration is halfway towards its new steady state. The cytochrome oxidase half-life in the liver derived from the rate of repair shown in Fig. 2 is about 6 days, or approximately 7-8 days if corrected for growth on the basis of increment in body weight. The close correspondence of this estimate of turnover with that of other mitochondrial components is consistent with the hypothesis that the rate of repair of the enzyme deficiency is determined in part by the rate of synthesis of new mitochondrial material. Cytochrome oxidase-deficient cells could then be considered as undergoing repair as other mitochondrial constituents are being renewed. The confirmation of this hypothesis requires a demonstration of interdependence between early cytochrome oxidase repair and other newly produced mitochondrial components.

\section{References}

1. Widdowson, E. M. 1964. Early nutrition and later development. In Diet and Bodily Constitution, Ciba Foundation, Study Group No. 17. E. G. W. Wolstenholme and M. O'Connor, editors. Little, Brown \& Co. Inc., Boston. 3.

2. Heath, C. W., M. B. Strauss, and W. B. Castle. 1932. Quantitative aspects of iron deficiency in hypochromic anemia. J. Clin. Invest. 11: 1293.

3. Shemin, D., and D. Rittenberg. 1946. The life span of the human red blood cell. J. Biol. Chem. 166: 627.

4. Bothwell, T. H., and C. A. Finch. 1962. Iron Metabolism. Little, Brown \& Co. Inc., Boston. 220.

5. Neuberger, A., and F. F. Richards. 1964. Protein biosynthesis in mammalian tissues. In Mammalian Protein Metabolism. H. N. Munro and J. B. Allison, editors. Academic Press, Inc., New York. $1: 243$.

6. Dallman, P. R., and H. C. Schwartz. 1965. Myoglobin and cytochrome response during repair of iron deficiency in the rat. J. Clin. Invest. 44: 1631.

7. Dallman, P. R., P. Sunshine, and Y. Leonard. 1967. Intestinal cytochrome response with repair of iron deficiency. Pediatrics. 39 : 863. 
8. McCall, M. G., G. E. Newman, J. R. P. O’Brien, L. S. Valberg, and L. J. Witts. 1962. Studies in iron metabolism: I. The experimental production of iron deficiency in the growing rat. Brit. J. Nutr. $16: 297$.

9. Owen, C. A. 1964. Distribution of copper in the rat. Am. J. Physiol. 207 : 446.

10. Cooperstein, S. J., and A. Lazarow. 1951. A microspectrophotometric method for the determination of cytochrome oxidase. J. Biol. Chem. 189: 665.

11. Burstone, M. S. 1961. Modifications of histochemical techniques for the demonstration of cytochrome oxidase. J. Histochem. Cytochem. 9: 59.

12. Rosenthal, O., and D. L. Drabkin. 1943. Spectrophotometric studies: XI. The direct micro spectrophotometric determination of cytochrome c. J. Biol. Chem. 149: 437.

13. Dallman, P. R., and H. C. Schwartz. 1965. Distribution of cytochrome $\mathrm{c}$ and myoglobin in rats with dietary iron deficiency. Pediatrics. 35: 677.

14. Brown, N. A., and R. G. Hemingway. 1962. A rapid method for the determination of copper in biological tissues by means of zinc dibenzyldithiocarbamate. Res. Vet. Sci. 3 : 345.

15. Crosby, W. H., J. I. Munn, and F. W. Furth. 1954. Standardizing a method for clinical hemoglobinometry. U. S. Armed Forces Med. J. $5: 693$.

16. Lowry, O. H., N. J. Rosebrough, A. L. Farr, and R. J. Randall. 1951. Protein measurement with the Folin phenol reagent. J. Biol. Chem. 193: 265.

17. Schneider, W. C. 1957. Determination of nucleic acids in tissues by pentose analysis. In Methods in Enzymology. S. P. Colowick and N. O. Kaplan, editors. Academic Press, Inc., New York. 3: 680.

18. Bray, G. A. 1960. A simple efficient liquid scintillator for counting aqueous solutions in a liquid scintillation counter. Analy. Biochem. 1: 279.

19. Dische, Z. 1955. Color reactions of nucleic acid components. In Nucleic Acids. E. Chargaff and J. N. Davidson, editors. Academic Press, Inc., New York. 285.

20. Schneider, W. C. 1948. Intracellular distribution of enzymes. III. The oxidation of octanoic acid by rat liver fractions. J. Biol. Chem. 176: 259.

21. Cohen, E., and C. A. Elvehjem. 1934. The relation of iron and copper to the cytochrome and oxidase content of animal tissues. J. Biol. Chem. 107 : 97.

22. Schultze, M. O. 1941. The relationship of copper to cytochrome oxidase and hematopoietic activity of the bone marrow of rats. J. Biol. Chem. 138: 219 .
23. Gallagher, C. H., J. D. Judah, and K. R. Rees. 1956. The biochemistry of copper deficiency. I. Enzymological disturbances, blood chemistry, and excretion of amino acids. Proc. Roy. Soc. (London), Ser. B. $145: 134$.

24. Gubler, C. J., G. E. Cartwright, and M. M. Wintrobe. 1957. Studies on copper metabolism. XX. Enzyme activities and iron metabolism in copper and iron deficiencies. J. Biol. Chem. 224: 533.

25. Messier, B., and C. P. Leblond. 1960. Cell proliferation and migration as revealed by radioautography after injection of thymidine- $\mathrm{H}^{3}$ into male rats and mice. Am. J. Anat. 106: 247.

26. Chance, B., and G. R. Williams. 1956. The respiratory chain and oxidative phosphorylation. Advan. Enzymol. 17: 65.

27. Bertalanffy, F. D., and C. Lau. 1962. Cell renewal. Intern. Rev. Cytol. 13: 357.

28. Enesco, M., and C. P. Leblond. 1962. Increase in cell number as a factor in the growth of the organs and tissues of the young male rat. J. Embryol. Exptl. Morphol. 10: 530.

29. Fletcher, M. J., and D. R. Sanadi. 1961. Turnover of rat-liver mitochondria. Biochim. Biophys. Acta. $51: 356$.

30. Lusena, C. V., and F. Depocas. 1966. Heterogeneity and differential fragility of rat liver mitochondria. Can. J. Biochem. $44: 497$.

31. Neubert, D., R. Bass, and H. Helge. 1966. Umsatzgeschwindigkeit der DNS in Mitochondrien von Warmbluterzellen. Naturwissenschaften. 53: 23.

32. Granick, S., and A. Gibor. 1967. The DNA of chloroplasts, mitochondria, and centrioles. Progr. Nucleic Acid Res. 6: 143.

33. Roodyn, D. B., J. W. Suttie, and T. S. Work. 1962. Protein synthesis in mitochondria. 2. A rate of incorporation in vitro of radioactive amino acids into soluble proteins in the mitochondrial fraction, including catalase, malic dehydrogenase and cytochrome c. Biochem. J. 83: 29.

34. Truman, D. E. S. 1964 . The fractionation of proteins from ox-heart mitochondria labelled in vitro with radioactive amino acids. Biochem. J. 91 : 59.

35. Kadenbach, B. 1966. Synthesis of mitochondrial proteins: demonstration of a transfer of proteins from microsomes into mitochondria. Biochim. Biophys. Acta. 134 : 430.

36. Segal, H. L., and Y. S. Kim. 1963. Glucocorticoid stimulation of the biosynthesis of glutamic-alanine transaminase. Proc. Natl. Acad. Sci. U. S. 50: 912. 